\title{
Asymmetric Miyaura-Michael Reaction with Polymeric Rh/Ag Catalysts
}

\section{Key words}

bimetallic nanoparticle catalysts

rhodium

silver

asymmetric 1,4-addition

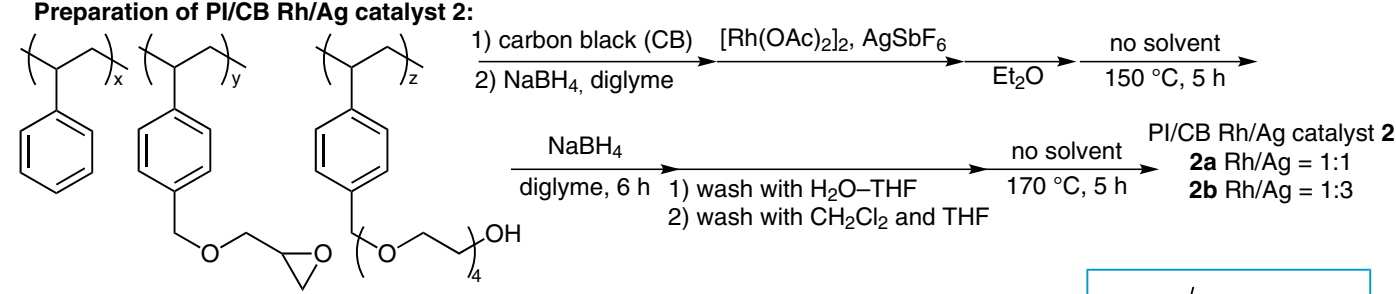

co-polymer 1 x:y:z = 29: 35: 36

Asymmetric 1,4-addition with $\mathrm{PI} / \mathrm{CB} \mathrm{Rh} / \mathrm{Ag}$ catalyst 2:

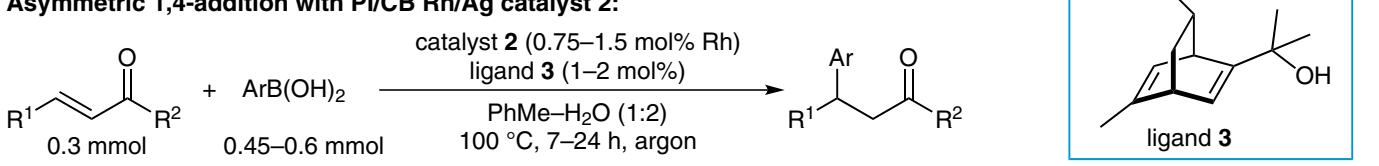<smiles>O=C1CCC[C@H](c2ccccc2)C1</smiles>

catalyst 2a quant., $98 \%$ ee<smiles>CC(C)(C)c1ccc([C@H]2CCCC(=O)C2)cc1</smiles><smiles>COc1ccc([C@H]2CCCC(=O)C2)cc1</smiles>

catalyst 2a $82 \%$ yield, $97 \%$ ee<smiles>Cc1ccccc1C1CCCC(=O)C1</smiles>

catalyst $2 \mathrm{a}$ $81 \%$ yield, $96 \%$ ee<smiles>O=C1CCC[C@H](c2ccc(F)cc2)C1</smiles>

catalyst 2a $87 \%$ yield, $98 \%$ ee<smiles>O=C1CC[C@@H](P)C1</smiles>

catalyst $\mathbf{2 a}$ $86 \%$ yield, $74 \%$ ee<smiles>Cc1cccc(C2CCCC(=O)C2)c1</smiles>

catalyst $2 \mathrm{a}$ $99 \%$ yield, $96 \%$ ee<smiles>COc1ccccc1[C@H]1CCCC(=O)C1</smiles>
catalyst 2a $95 \%$ yield, $93 \%$ ee<smiles>CC(CC(=O)c1ccccc1)c1ccccc1</smiles>

catalyst $\mathbf{2 b}$ $72 \%$ yield, $92 \%$ ee
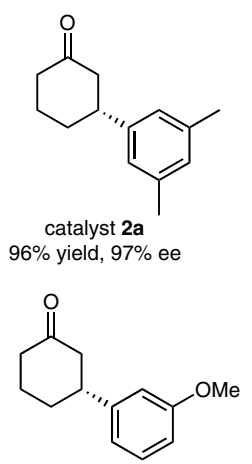

catalyst $\mathbf{2 a}$ $93 \%$ yield, $98 \%$ ee<smiles>CCCCCC[C@H](CC(C)=O)c1ccccc1</smiles>

catalyst $\mathbf{2 b}$ $70 \%$ yield, $95 \%$ ee
Significance: Polystyrene-based polymer-incarcerated bimetallic rhodium nanoparticle catalysts $\mathrm{Pl} / \mathrm{CB} \mathrm{Rh} / \mathrm{Ag} \mathbf{2 a}-\mathbf{b}$ were prepared from copolymer 1, carbon black (CB), $\left[\mathrm{Rh}(\mathrm{OAc})_{2}\right]_{2}$, and $\mathrm{AgSbF}_{6}$. Asymmetric 1,4-addition of arylboronic acids to enones was carried out with 2 and chiral ligand $\mathbf{3}$ to give the corresponding ketones in 70-99\% yield with 74-98\% ee without leaching of rhodium.
Comment: Catalyst 2a was reused 13 times for the reaction of phenylboronic acid with 2-cyclohexenone. After the $10^{\text {th }}$ use, the recovered catalyst was heated at $170{ }^{\circ} \mathrm{C}$ to regain its catalytic activity $\left(1^{\text {st }}-8^{\text {th }}\right.$ use: $>94 \%$ yield, $9^{\text {th }}$ use: $67 \%$ yield, $10^{\text {th }}$ use: $60 \%$ yield, $11^{\text {th }}-14^{\text {th }}$ use: $>90 \%$ yield, with $98 \%$ ee in all cycles).

SYNFACTS Contributors: Yasuhiro Uozumi, Yoichi M. A. Yamada, Yoshinari Yuyama

Dol: 10.1055/s-0032-1317915; Reg-No.: Y14312SF 